\title{
Phosphorylation Status of Fas-Associated Death Domain-Containing Protein Regulates Telomerase Activity and Strongly Correlates with Prostate Cancer Outcomes
}

\author{
Yoshiaki Matsumura $^{a}$ Keiji Shimada ${ }^{b}$ Nobumichi Tanaka ${ }^{a}$ Kiyohide Fujimoto ${ }^{a}$ \\ Yoshihiko Hirao $^{a}$ Noboru Konishi ${ }^{b}$ \\ Departments of a Urology and ${ }^{\mathrm{b}}$ Pathology, Nara Medical University, Nara, Japan
}

\section{Key Words}

FADD phosphorylation - hTERT • Prostate cancer

\begin{abstract}
Objectives: We investigated whether the phosphorylated Fas-associated death domain protein (FADD) at serine 194 regulated human telomerase reverse transcriptase (hTERT) expression, telomerase activity and cancer progression using prostate cancer cell lines and radical prostatectomy samples taken from patients receiving neoadjuvant hormonal therapy (NHT). Methods: We analyzed hTERT expression, telomerase activity and invasion capacity in prostate cancer cell lines overexpressing the wild-type or mutant form of FADD (S194D or A). FADD, phosphorylated FADD ( $p-F A D D)$ and hTERT expression in viable prostate cancer cells following NHT were immunohistochemically examined using 50 prostatectomy samples. Results: Dephosphorylated FADD (S194A) overexpression enhanced hTERT expression and telomerase activity, resulting in increased cell proliferation and invasion capacity. In Kaplan-Meier survival analysis, the patients with prostate cancer expressing low levels of $p$ FADD and high levels of hTERT had significantly higher rates
\end{abstract}

of biochemical recurrence than those with high $p-F A D D$ and low hTERT expression $(p<0.001)$. Conclusions: The phosphorylation status of FADD at serine 194 could strongly affect survival and invasion of prostate cancer cells via modulation of hTERT expression and telomerase activity. p-FADD and hTERT expression may have potential as new biomarkers predicting the biochemical recurrence after NHT.

Copyright $\odot 2009$ S. Karger AG, Basel

\section{Introduction}

Prostate cancer is one of the most commonly diagnosed cancers, and one of the leading causes of cancerrelated deaths around the world, including Japan. The rationale for combined modality treatment, such as radical prostatectomy and external beam radiation therapy with neoadjuvant hormonal therapy (NHT), has recently attracted attention, although not yet established in the routine clinical practice. For patients undergoing radical prostatectomy, NHT has reportedly achieved good results [1]. However, NHT does not yield any improvement in the overall and disease-free survival [2], and it remains

\section{KARGER}

Fax +4161306 1234 E-Mail karger@karger.ch www.karger.com
(C) 2009 S. Karger AG, Basel

1015-2008/09/0766-0293\$26.00/0

Accessible online at:

www.karger.com/pat
Dr. Yoshiaki Matsumura

Department of Urology, Nara Medical University

840 Shijo-cho, Kashihara, Nara 634-8522 (Japan)

Tel. +81 74422 3051, ext. 2238, Fax +81 744229282

E-Mail ymatsumu@tcc.pref.tochigi.jp 
controversial whether NHT before radical prostatectomy is useful for cancer control. Moreover, we have no biological markers to assess the malignant potential of viable cancer cells (so-called hormone-resistant cells) following NHT to predict cancer progression. Unfortunately, morphological assessment of the therapeutic effects using radical prostatectomy specimens does not significantly correlate with the biochemical recurrence rate.

The Fas-associated death domain-containing protein (FADD) was originally identified as an adapter molecule for Fas-mediated apoptosis [3, 4], and it is now well known to play an important role in the formation of the deathinducing signaling complex following Fas stimulation [5]. Recent reports have shown that FADD is exclusively phosphorylated at the C-terminal serine 194, specifically at the G2/M cell cycle arrest, suggesting a close association with cell cycle regulation [6]. FADD is phosphorylated at serine 194, which is implicated in cell cycle progression but not associated with the sensitivity to Fas-mediated apoptosis. Analysis of FADD mutant null mice revealed that FADD also plays a role in embryonic development, cell cycle control and proliferation of lymphoid cells $[7,8]$. Moreover, we have demonstrated that the phosphorylated FADD (p-FADD) is highly expressed in prostate cancer cells of lower Gleason score using prostatectomy samples without NHT [9]. Taken together, FADD phosphorylation could lead to suppression of prostate cancer progression. However, the biological role of the dephosphorylated FADD in prostate cancer cells has not been identified yet. Moreover, it remains unclear whether the phosphorylation status of FADD is modified in response to NHT or not. We focused on human telomerase reverse transcriptase (hTERT), which is involved in cancer growth [10], as the downstream molecule of the dephosphorylated FADD.

In this study, we investigated whether the phosphorylation status and hTERT expression in cancer cells could be useful biomarkers to estimate the malignant potential and to predict the prognosis of human prostate cancers, and moreover, whether these molecules might be the best therapeutic targets.

\section{Materials and Methods}

Cell Culture, Plasmids and Chemicals

Human prostate cancer cell lines (PC-3) were purchased from American Type Culture Collection (Manassas, Va., USA) and cultured in RPMI supplemented with $10 \%$ fetal bovine serum. FLAGtagged human FADD and mutant FADD: S194 $\rightarrow$ A (dephosphorylation-mimicking form) and S194 $\rightarrow$ D (phosphorylation-mim- icking form) were prepared as described previously [11]. Anti-wild-type FADD (WT-FADD) was purchased from BD Pharmingen (Tokyo, Japan); anti-p-FADD at S194 from Cell Signaling (Beverly, Mass., USA) and anti-hTERT from Santa Cruz Biotechnology (Santa Cruz, Calif., USA).

Reverse Transcription-Polymerase Chain Reaction

RNA was extracted with Trizol reagent and subjected to reverse transcription-polymerase chain reaction (RT-PCR) using the onestep RT-PCR kit (Qiagen, Tokyo, Japan) according to the manufacturer's protocol. The PCR condition was at $94^{\circ} \mathrm{C}$ for $1 \mathrm{~min}$, at $59^{\circ} \mathrm{C}$ (hTERT) $/ 60^{\circ} \mathrm{C}(\mathrm{GAPDH})$ for $30 \mathrm{~s}$ and at $72^{\circ} \mathrm{C}$ for $1 \mathrm{~min}$, for 35 cycles. Human specific primers, which we designed using the Primer Quest program, were purchased from IDT (Coralville, Iowa, USA). hTERT-F, 5'-CTACTCCTCAGGCGACAAGG-3'; hTERT-R, 5'-TGGAACCCAGAAAGATGGTC-3'; glyceraldehyde-3-phosphate dehydrogenase (GAPDH)-F, 5'-ACCACAGTCCATGCCATCAC-3', and GAPDH-R, 5'-TCCACCACCCTGTTGCTGTA-3' were used. The PCR products were analyzed on $1.5 \%$ agarose gel and visualized by ethidium bromide staining.

\section{Telomeric Repeat Amplification Protocol Assay}

The cells were homogenized in lysis buffer and 0.5\% 3-[(3cholamidopropyl)dimethylammonio]-1-propane sulfonate, and incubated on ice for $30 \mathrm{~min}$. The cell lysate was clarified by centrifugation at $14,000 \mathrm{~g}$ for $20 \mathrm{~min}$ at $4^{\circ} \mathrm{C}$, and the supernatants were freshly frozen at $-80^{\circ} \mathrm{C}$. Telomerase activity was determined using the TRAP-eze telomerase detection kit S7700 kit (Chemicon International, Temecula, Calif., USA). The gel was stained with silver using Ezstain Silver (Atto, Tokyo, Japan).

\section{Chick Chorioallantoic Membrane Assay}

In vivo cancer cell invasion and intravasation assays were carried out using 11-day-old chick embryos wherein $10^{6}$ cancer cells transfected with the green fluorescent protein (GFP)-encoding vector pEGFP (Clontech, Palo Alto, Calif., USA) with FLAGtagged human FADD and mutant FADD (S194A FADD and S194D FADD). After 24-hour culture, the cells were seeded on the chorioallantoic membrane (CAM) for 3 days [12]. After collection of the CAM samples, the tissues were fixed and stained with antiGFP. Thereafter, the number of invading cancer cells positive for GFP was counted in three or more randomly selected fields. At least three CAMs were used in each experiment.

Cell Viability Assay

The cells were cultured in a medium containing fetal bovine serum for 4 days. After incubation, MTT [3-(4,5-dimethylthiazol-2-yl)-5-(3-carboxymethoxyphenyl)-2-(4-sulfonyl)-2H tetrazolium, inner salt] reagent (Promega, Tokyo, Japan) was added, and optical absorbance at $490 \mathrm{~nm}$ was measured every day using a microplate reader [11].

Terminal Deoxynucleotidyl Transferase-Mediated dUTP Nick End Labeling Assay

We detected DNA cleavage, a characteristic of apoptosis, using the terminal deoxynucleotidyl transferase-mediated dUTP nick end labeling (TUNEL) assay, as directed by the manufacturer (GenScript, Piscataway, N.J., USA). Images of nuclear fluorescence typical of apoptotic cells were taken by fluorescence microscopy as previously described, examining at least 600 cells 
Table 1. Patient characteristics at diagnosis

\begin{tabular}{lccc}
\hline \multirow{2}{*}{ Characteristics } & \multicolumn{2}{c}{ Biochemical recurrence } & \multirow{2}{*}{ p value } \\
\cline { 2 - 3 } & yes $(\mathrm{n}=18)$ & no $(\mathrm{n}=32)$ & \\
\hline Mean age, years & 69.6 & 69.4 & \multirow{2}{*}{0.71} \\
PSA & 41.1 & 16.5 & \\
$\quad \leq 10 \mathrm{ng} / \mathrm{ml}$ & $2(11 \%)$ & $14(44 \%)$ & \\
$10.1-20 \mathrm{ng} / \mathrm{ml}$ & $3(17 \%)$ & $12(38 \%)$ & \\
$\geq 20 \mathrm{ng} / \mathrm{ml}$ & $13(72 \%)$ & $6(19 \%)$ & 0.001 \\
Gleason score & & & \\
$\leq 6$ & $2(11 \%)$ & $15(47 \%)$ & \\
7 & $10(56 \%)$ & $5(16 \%)$ & \\
$8-10$ & $5(28 \%)$ & $10(31 \%)$ & \\
Unknown & $1(6 \%)$ & $2(6 \%)$ & 0.015 \\
Clinical stage & & $12(38 \%)$ & \\
T1c & 0 & $15(47 \%)$ & \\
T2a-b & $12(67 \%)$ & $5(16 \%)$ & 0.010 \\
T3-4 & $6(33 \%)$ & & \\
\hline
\end{tabular}

from three different fields in each experiment; cell death was expressed as percentage of the TUNEL-positive cells [13].

\section{Patients and Treatment}

We used tissue specimens from 50 patients considered as noneffective cases of NHT who underwent radical prostatectomy following NHT between 1997 and 2004 at our hospital. 'Non-effective' case means that almost all cancer cells were viable or less than one half of cancer cells were non-viable. The patients' age ranged from 53 to 75 (median: 70.5) years. The median prostatespecific antigen (PSA) level at biopsy was $13.95 \mathrm{ng} / \mathrm{ml}$ (range: 6.0 $36.3 \mathrm{ng} / \mathrm{ml}$; Tandem-R assay). NHT consisted of maximum androgen blockade with a luteinizing hormone-releasing hormone agonist either alone (8 patients/16\%) or combined with an antiandrogen agent (42 patients/84\%) The median NHT duration was 6.6 (range: 4-12) months. All patients underwent serum PSA testing at least every 3 months after surgery. A PSA level $\geq 0.2 \mathrm{ng} / \mathrm{ml}$ after surgery was defined as biochemical recurrence. The median follow-up period after radical prostatectomy was 45.7 (range: 17102) months. The Human Ethics Review Committee of Nara Medical University approved the study protocol. The PSA levels at diagnosis, the Gleason score at biopsy and the clinical T stage are shown in table 1.

\section{Immunohistochemistry}

The sections were incubated for $16 \mathrm{~h}$ at $4^{\circ} \mathrm{C}$, and the reactions were visualized using a Histofine SAB-PO kit and diaminobenzidine as chromogen (Nichirei, Tokyo, Japan), with hematoxylin counterstaining.

\section{Statistical Analysis}

Fisher's exact probability tests were used for the assessment in the proliferation assay and the clinical parameters of biochemical recurrence. Wilcoxon signed-rank tests were used to evaluate the invading cancer cell numbers of mutant FADD and the relation- ship between the percentages of p-FADD-positive cells and the intensity of hTERT expression. Kaplan-Meier survival curves and log-rank tests were used for survival analysis of biochemical recurrence. The results were considered significant if $\mathrm{p}<0.05$.

\section{Results}

\section{Phosphorylation Status of FADD at S194 Correlates} with hTERT Expression and Telomerase Activity

To clarify the effect of the dephosphorylated form of FADD on telomerase activity, we constructed PC-3 cells stably overexpressing FLAG-tagged plasmids encoding the wild-type and mutant form of FADD, in which serine 194 was replaced by alanine (S194A, mimicking dephosphorylated FADD) or glutamate (S194D, mimicking pFADD). Among several clones resistant to hygromycin $\mathrm{B}$, we selected a single clone fully expressing the wildtype or mutant forms of FADD, as determined by immunoblotting using anti-FLAG antibody (fig. 1A). The level of expression of hTERT $m$ RNA and protein was minimal in the control clone (expressing hygromycin-B-resistant gene only), but it was greatly increased by overexpression of the wild-type or S194A FADD, resulting in enhancement of the telomerase activity in PC3 cells (fig. 1B, C). In the clones overexpressing S194D FADD, both hTERT expression and telomerase activity were not significantly changed, indicating that the dephosphorylated form of FADD might play an essential role in the telomerase activity through inducing hTERT in prostate cancer cells.

\section{Phosphorylation Status of FADD at S194 Regulates \\ Prostate Cancer Proliferation, Invasion and \\ Sensitivity to Anti-Cancer Agents}

Next, we examined the effects of the phosphorylation status of FADD at serine 194 on cell proliferation by MTT assay. As shown in figure $2 \mathrm{~A}$, the cell number increased to the same extent within the 48-hour incubation in the controls and clones expressing the wild-type and mutant form of FADD. However, thereafter, the proliferation rate of cells was much more increased in the clones expressing the wild-type or S194A FADD than in those with S194D FADD expression or the control. Finally, the effects of FADD phosphorylation on cancer invasion were analyzed using the in vivo CAM assay. The cells were transfected with vector encoding GFP for $12 \mathrm{~h}$, and then implanted on CAM. After 5 days, the membranes were extracted and the invasion capacity was assessed by examining the number of GFP-pos- 


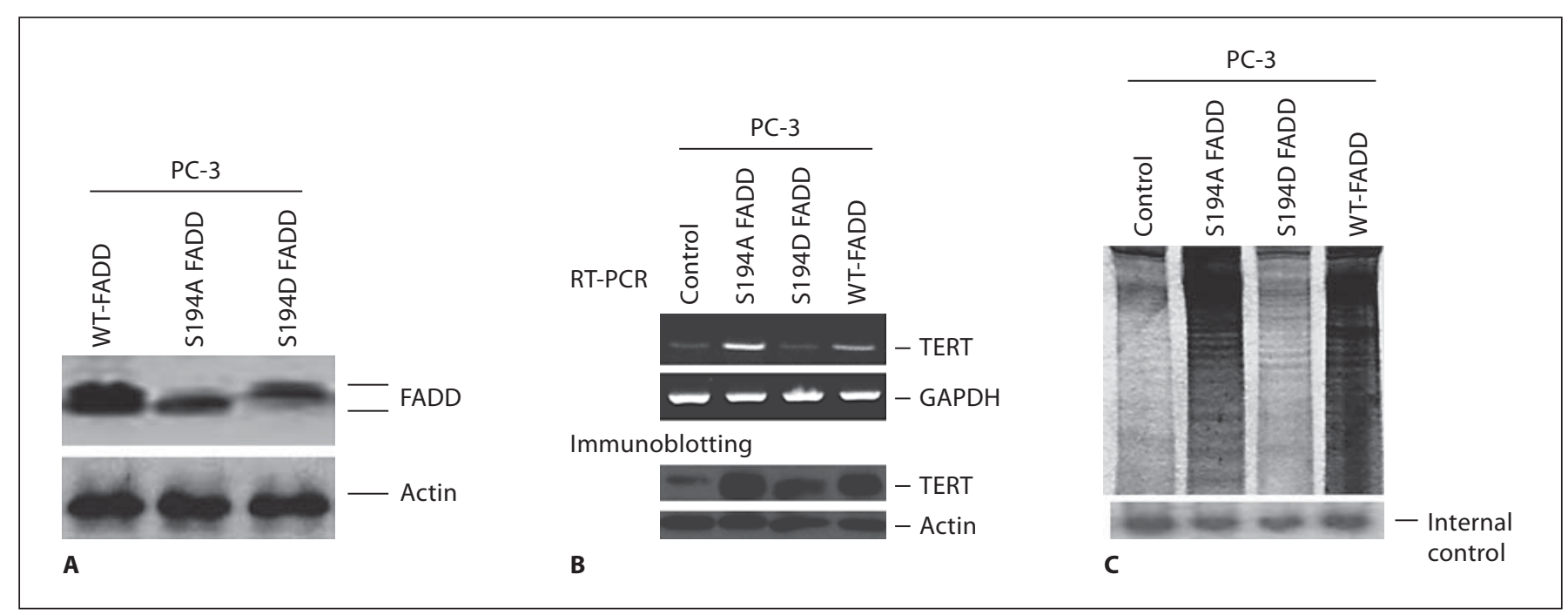

Fig. 1. The phosphorylation status of FADD regulated hTERT expression and telomerase activity. The sequence of the C-terminal domain of FADD harbors key phosphorylation sites at serine 194. PC-3 cells were transfected with the hygromycin B resistance gene with a FLAG-tagged vector encoding S194A and S194D mutant FADD and WT-FADD. A Whole lysates overexpressing A194,
D194 and WT were examined by Western blotting using antiFADD and anti-actin antibodies. B RNA was extracted, and RTPCR assays were done to detect hTERT mRNAs. Whole lysates were examined by Western blotting using anti-TERT and anti-actin antibodies. C Cell pellets were collected and subjected to TRAP assay. itive invading cells as identified by green fluorescence (fig. 2B). The invading cell numbers were significantly increased by the wild-type or S194A FADD overexpression but not by S194D FADD (fig. 2C). When we obtained graft samples on day 3 after implantation, the numbers of invading cells were not significantly different among these clones, being consistent with the results of the in vitro MTT assay (data not shown). Taken together, the dephosphorylated form of FADD could enhance cell growth and invasion capacity in human prostate cancer cells. In addition, we examined the sensitivity of anti-cancer agents in the clone overexpressing empty vector, WT-FADD, S194A and S194D using TUNEL staining. The sensitivities of PC3 cells to cisplatin and etoposide were greatly increased by overexpression of the wild-type and S194D FADD. Moreover, the sensitivities to cisplatin and etoposide in the clones expressing S194D FADD were higher than in the wild type. In contrast, in the clones overexpressing S194A FADD, the sensitivities to cisplatin and etoposide were not significantly changed, indicating that the phosphorylated form of FADD might induce the susceptibility to anti-cancer agents (fig. 2D). Nonetheless, the dephosphorylated FADD did not reduce the susceptibility to anti-cancer agents because PC-3 is originally less sensi- tive to the anti-cancer agents. To clarify the induction of apoptosis by FADD transfection, we examined the apoptotic status by TUNEL staining. The transfection of FADD induced apoptosis, but the rates of apoptosis were only minimal. Besides, induction of apoptosis was not significantly different between the clones expressing WT-FADD, S194A FADD and S194D FADD (data not shown).

\section{Expression of Phosphorylated FADD/hTERT in \\ Prostate Cancer Cells and Biochemical Recurrence following NHT}

FADD, p-FADD and hTERT expressions were immunohistochemically analyzed using radical prostatectomy samples following NHT. As shown in figure 3A, FADD was equally expressed in the cases with and without biochemical recurrence. Nevertheless, p-FADD expression at serine 194 was increased in cancer cells without recurrence. Phosphorylated FADD expression was considered positive when $>15 \%$ (median level in all specimens) of the cancer cells showed positive immunostaining. As demonstrated in figure 3B, Kaplan-Meier analysis showed that the biochemical recurrence-free survival rate of the $\mathrm{p}$-FADD-positive cases was significantly higher than that of the -negative cases $(p<0.001)$. 


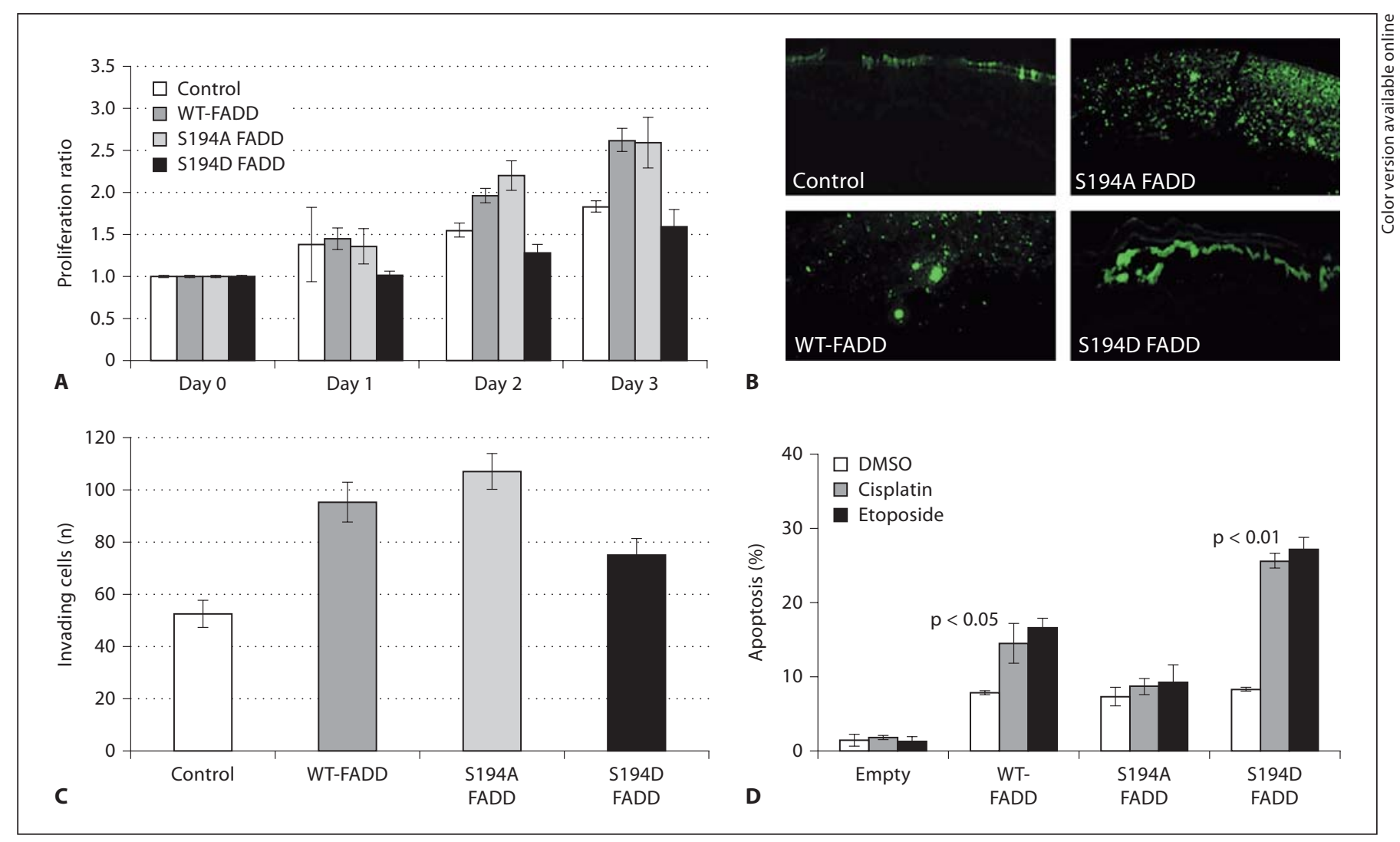

Fig. 2. Phosphorylation status of FADD at serine 194 regulated the cell proliferation and invasion in prostate cancer cells. A PC-3 cells were co-transfected with a $\beta$-gal-encoding vector with and without FLAG-tagged WT-FADD and mutant FADD (S194A and S194D). After a 1-day incubation, cell survival after 2, 3 and 4 days in the medium was analyzed by MTT assay. The experiments were performed at least in triplicate. B, C PC-3 cells were transfected with GFP-encoding plasmids in the presence of control, WTFADD, S194A mutant FADD and S194D mutant FADD. After
$24 \mathrm{~h}$ in culture, cells were plated on CAM, and grafts were collected after 3 days. The tissues were fixed and stained with antiGFP, and, thereafter, the number of invading GFP-positive cancer cells was quantified in three or more randomly selected fields. D p-FADD at serine 194 induced susceptibility to anti-cancer agents. After a 48-hour incubation with $10 \mu \mathrm{M}$ cisplatin and etoposide, the apoptotic rates induced by these agents were analyzed by TUNEL stain.
In contrast to the p-FADD, hTERT was not or little expressed in the cancer cells without recurrence, whereas it was highly expressed in those with biochemical recurrence (fig. 4A). In the present study, the intensity of immunostaining of hTERT was divided into three levels (mild, moderate and strong), and it closely correlated with protein expression levels assessed by immunoblotting (fig. 4B). Furthermore, the biochemical recurrencefree survival rate of the patients with low levels of hTERT was significantly greater than in those with high-level expression ( $p<0.001$; fig. $4 \mathrm{C})$. There was a significant inverse correlation between the percentages of the $\mathrm{p}$ FADD-positive cells and the staining intensity of hTERT as follows: the positive percentage of the p-FADD was
$28.9 \pm 12.1,15.6 \pm 10.8$ and $10.5 \pm 6.1 \%$ in the mild, moderate and strong intensities of hTERT, respectively (fig. 5).

\section{Discussion}

We have already demonstrated that transition from dephosphorylation to phosphorylation of FADD at serine 194 could lead to cell cycle arrest and growth suppression in human prostate and breast cancer cells [9]. However, the biological roles of dephosphorylated FADD in prostate cancer cells have not been investigated yet. In our present in vitro experiments using the wild-type or 
Fig. 3. A Phosphorylation status of FADD at serine 194 in prostate cancer cells. The specimens were obtained from patients undergoing radical prostatectomy following NHT with (a, b) and without biochemical recurrence $(\mathbf{c}, \mathbf{d})$, and were stained with anti-FADD $(\mathbf{a}, \mathbf{c})$ and anti- p-FADD (b, d) antibodies. a, c $\times 100$. b, d $\times 200$. B Kaplan-Meier biochemical recurrencefree survival curve according to p-FADD expression (log-rank test: $\mathrm{p}<0.001$ ). $\mathrm{p}$ FADD expression was considered positive when $>15 \%$ (median level in all specimens) of the cancer cells showed positive immunostaining.

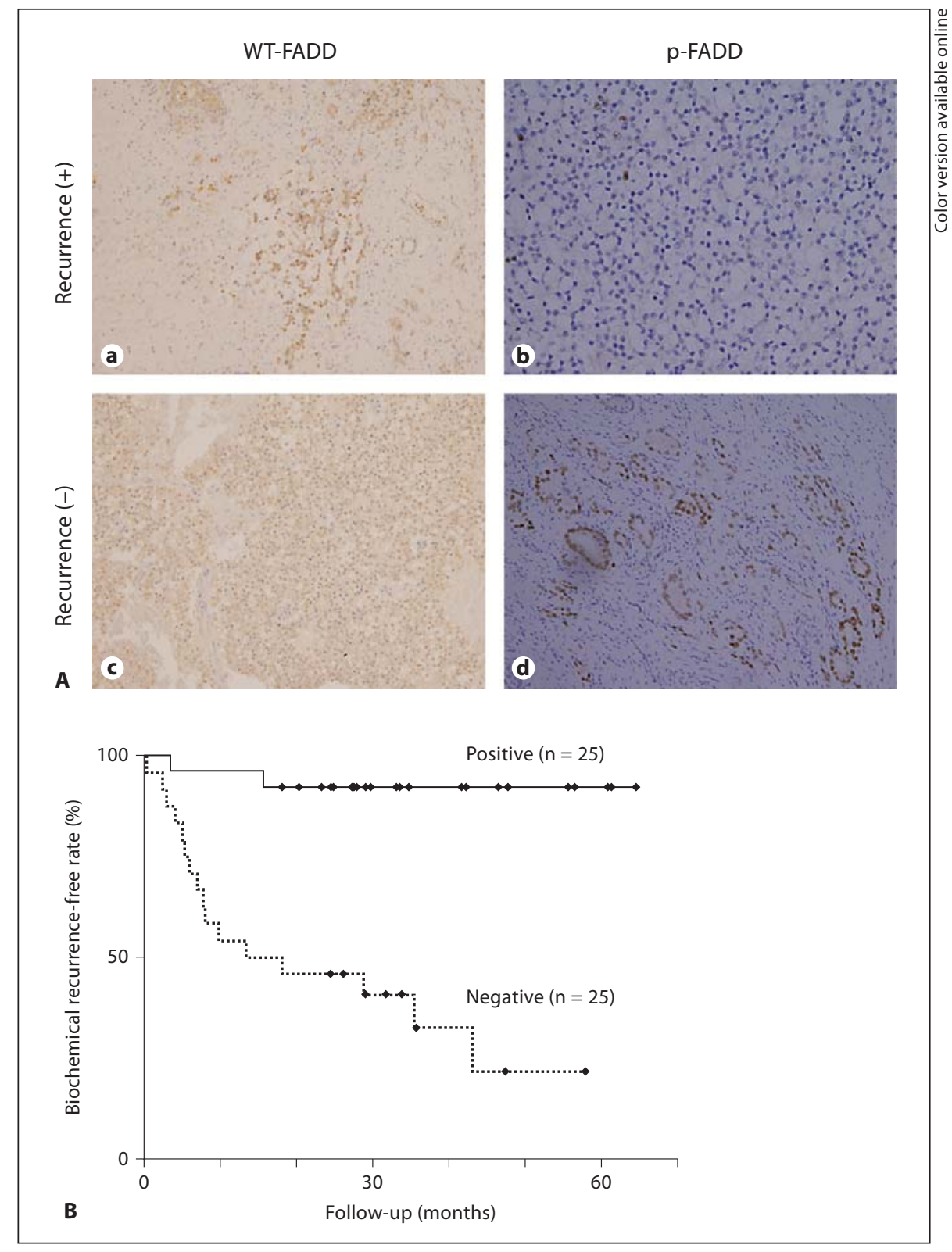

phosphorylation-/dephosphorylation-mimicking mutant forms of FADD and human prostate cancer cell lines, we clearly demonstrated for the first time that the dephosphorylated FADD significantly enhanced cancer cell growth through inducing hTERT expression. Telomerase is a ribonucleoprotein enzyme with specialized reverse transcriptase activity that catalyzes the synthesis and extension of telomeric DNA $[14,15]$. The telomerase complex is composed of the catalytic subunit reverse transcriptase protein hTERT [16], the telomerase RNA template subunit, hTR [17] and other associated proteins
[18]. Telomerase activity is typically absent in most normal human cells, but it is expressed in nearly all human cancer cells. Besides, a strong correlation is observed between hTERT mRNA expression and telomerase activity in various epithelial cancers indicating that hTERT may be mostly transcriptionally regulated [19]. The activity of telomerase, hTERT induction and cancer cell proliferation were accelerated by overexpression of the wildtype and dephosphorylated mutant FADD. Moreover, it was more prominent in cases showing overexpression of the dephosphorylated mutant FADD (S194A) but not the 

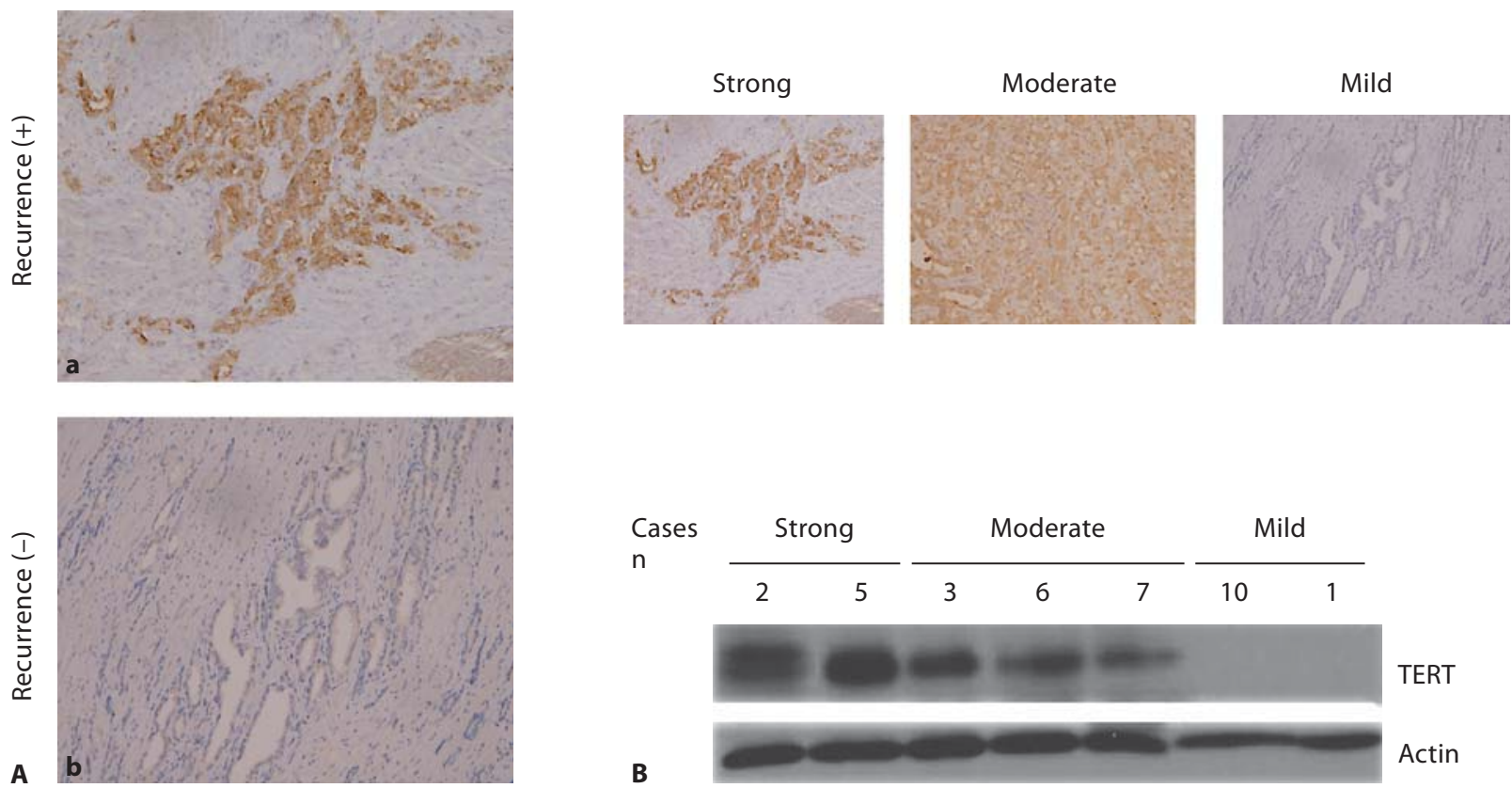

Fig. 4. hTERT expression in prostate cancer cells. A The specimens were obtained from patients undergoing radical prostatectomy following NHT with (a) and without biochemical recurrence $(\mathbf{b})$. They were stained with anti-TERT antibodies. $\times 100$. B Immunohistochemical staining intensity of hTERT was divided into three levels (mild, moderate and strong). Immunoblotting analysis of TERT protein expression in the specimens from the patients undergoing radical prostatectomy and NHT. C KaplanMeier biochemical recurrence-free survival curve according to the hTERT expression (log-rank test: $\mathrm{p}<0.001)$.

phosphorylated mutant FADD (S194D). Similar results were also observed regarding the invasion capacity as follows: the invading cell number of the prostate cancer cell line was significantly increased compared with the wild-type and dephosphorylated FADD, but not by the p-FADD. These FADD-mediated effects on cell proliferation and invasion were strongly suppressed by silencing of hTERT by siRNA transfection (data not shown). hTERT induction and its dependent increase in telomerase activity are considered to be mainly involved in the

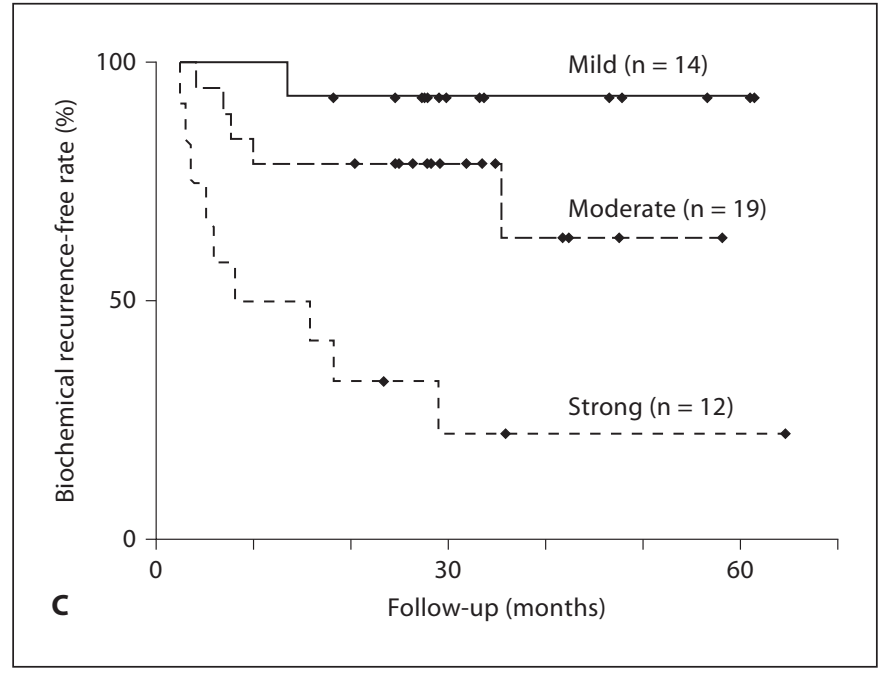

mechanisms. To verify this hypothesis, we examined several molecules associated with invasion or migration, including matrix metalloproteinases 2 and 9 , and urokinase-type plasminogen activator, but the protein/mRNA levels or gelatinolytic activity was not significantly changed by FADD overexpression. In addition, the fold increase in cell proliferation by FADD transfection was almost similar to that of the invading cell number (fig. 2A, C). Therefore, FADD status-mediated enhancement of cancer invasion is closely dependent on the in- 


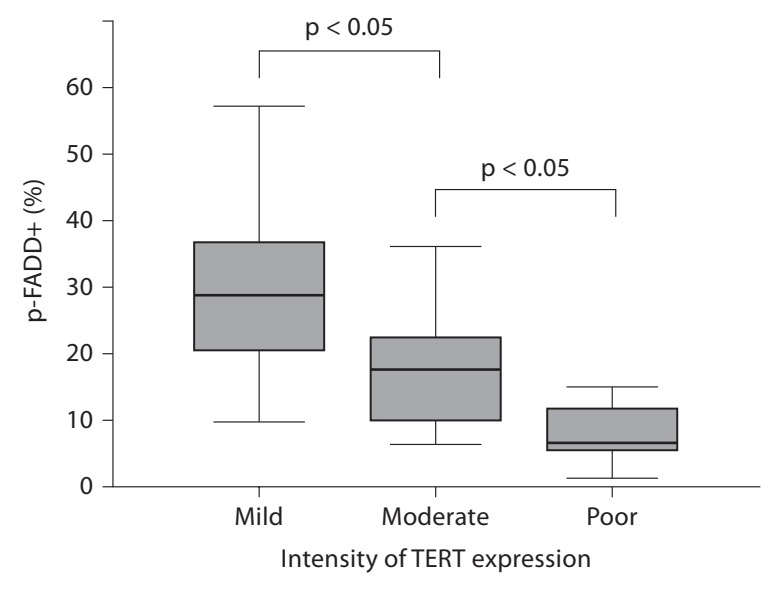

Fig. 5. Box plots showing the correlation between the positivity for the p-FADD and the intensity of hTERT.

crease in cell growth. FADD is a well-known key molecule that mediates apoptosis induction by Fas, tumor necrosis factor (TNF) or TNF-related apoptosis-inducing ligands, and the cells lacking FADD show resistance to receptor-mediated cell death [20]. In contrast, Chen et al. [21] have recently provided evidence for a strong correlation between overexpression of FADD mRNA and protein in human lung adenocarcinomas and a poor clinical outcome. Furthermore, Amit et al. [22] demonstrated that FADD could induce NF- $\kappa \mathrm{B}$, which plays a central role in tumor development, progression and therapy. Taken together, FADD and the dependent signals have suppressive and promotive effects on human cancer [23]. In contrast to our present data, Chen et al. [21] indicated that the phosphorylated form of FADD induces NF- $\kappa B$, perturbs the cell cycle and is associated with progression of the biological behavior of lung adenocarcinomas. A recent study on acute myeloid leukemia has shown that the absence or low expression of FADD protein is a poor prognostic factor [24]. These contradictory results might be due to cell-type-specific aberrations in dichotomous FADD-mediated pathways that regulate both cell growth and apoptosis. Studies using immunohistochemistry and subcellular fractionation analysis revealed that FADD is a predominantly nuclear protein in many cell lines $[25,26]$. Our present results showed that the phosphorylated form of FADD was localized in the nucleus, whereas FADD was localized in both the cytoplasm and nucleus (fig. 3A). Consequently, we speculate there are key proteins localized in the cytoplasmic fraction that can interact with the dephosphorylated FADD and translocate into the nucleus followed by acceleration of hTERT transcription. As we still have no conclusive evidence, this issue should be further evaluated. We found no mutation at serine194 in prostate cancer specimens in the present study (data not shown). Therefore, transition from dephosphorylation to phosphorylation might be the best target for a useful cancer therapy. Taxanes are reportedly one of the candidates that can successfully phosphorylate FADD at serine194 $[9,27]$. Since taxanes including docetaxel are useful anti-cancer drugs for prostate cancer and are currently used worldwide [28, 29], FADD phosphorylation can be a biomarker to evaluate the therapeutic outcome.

A more important finding in the present study is that the p-FADD at serine 194 and hTERT expression are available biomarkers to predict the biochemical recurrence following neoadjuvant androgen withdrawal therapy. Increased positive percentage for the p-FADD and low expression of hTERT are significantly associated with a good prognosis following NHT. Furthermore, there was a strong correlation between the percentages of positive cells for p-FADD and the intensity of hTERT, and this is consistent with our analyses in vitro and in vivo. The prostate cancer cells used in the immunohistochemical analysis were all morphologically determined as 'viable' cells, and therefore, these biomarkers can estimate the clinical effects of NHT independently from the morphological or pathological assessment.

To date, there are no useful tools to analyze the therapeutic effects using radical prostatectomy samples following NHT other than the pathological methods. However, it is well known that the morphological analysis tends to lack reproducibility and reliability, because due to marked degeneration of the remaining cancer cells, we cannot accurately assess whether the cells have low or high malignant potential or no malignancy by pathological examinations only. In fact, we have encountered cases with good outcome although the pathological assessment showed poor response to NHT. From the present data, the positivity for the p-FADD and hTERT could be a novel marker to determine whether the therapeutic response is good or not. In our previous report, WTFADD expression in both normal prostate epithelial cells and cancer cells was not significantly different [9]. The present study showed that the expression of WT-FADD in a patient with biochemical recurrence was equal to that in recurrence-free cases. Thus, we suggested that 
dephosphorylated FADD could enhance hTERT expression of prostate cancer following NHT. Furthermore, induction of dephosphorylated FADD to p-FADD, i.e. reduction of the dephosphorylated FADD by NHT, might improve the therapeutic benefit. On the other hand, no induction of p-FADD by NHT was associated with a poor prognosis. In addition, $\mathrm{p}$-FADD enhanced the sensitivity to anti-cancer agents, but dephosphorylated FADD did not change it (fig. 2D). We found that FADD phosphorylation at Ser194 was associated with paclitaxel-induced upregulation of MEK kinase 1 expression and enhancement of the downstream c-jun NH2-terminal kinase (JNK) pathway by which prostate cancer cells were highly sensitized to apoptosis by etoposide or cisplatin. We speculated that the enhancement of TERT modulating the dephosphorylated FADD could implicate inhibition of JNK activation or inhibition of the JNK induction of apoptosis.
The initial purpose of this study was to determine a useful predictor of biochemical recurrence in patients who underwent radical prostatectomy with NHT. A decade ago, lots of patients received NHT prior to radical prostatectomy. Indeed, $48.5 \%$ of patients had NHT at our institute between 1997 and 2004. Nowadays, most patients who undergo radical prostatectomy are hormone naïve. Therefore, an additional study similar to this one is currently being conducted on hormone-naïve patients who underwent radical prostatectomy.

In summary, the transition from the p-FADD to the dephosphorylated form of FADD induced the activation of telomerase through hTERT transcriptional activity. Moreover, p-FADD and hTERT expression have potential as new biomarkers to predict the rate of biochemical recurrence in patients undergoing radical prostatectomy following NHT.

\section{References}

1 Witjes WP, Schulman CC, Debruyne FM: Preliminary results of a prospective randomized study comparing radical prostatectomy versus radical prostatectomy associated with neoadjuvant hormonal combination therapy in T2-3 N0 M0 prostatic carcinoma. The European Study Group on Neoadjuvant Treatment of Prostate Cancer. Urology 1997; 49:65-69.

-2 Klotz LH, Goldenberg SL, Jewett MA, Fradet Y, Nam R, Barkin J, Chin J, Chatterjee S: Long-term followup of a randomized trial of 0 versus 3 months of neoadjuvant androgen ablation before radical prostatectomy. J Urol 2003;170:791-794.

-3 Boldin MP, Goncharov TM, Goltsev YV, Wallach D: Involvement of $\mathrm{MACH}$, a novel MORT1/FADD-interacting protease, in Fas/ APO-1- and TNF receptor-induced cell death. Cell 1996;85:803-815.

$\checkmark 4$ Chinnaiyan AM, O’Rourke K, Tewari M, Dixit VM: FADD, a novel death domaincontaining protein, interacts with the death domain of Fas and initiates apoptosis. Cell 1995;81:505-512.

5 Tibbetts MD, Zheng L, Lenardo MJ: The death effector domain protein family: regulators of cellular homeostasis. Nat Immunol 2003;4:404-409.

6 Scaffidi C, Volkland J, Blomberg I, Hoffmann I, Krammer PH, Peter ME: Phosphorylation of FADD/MORT1 at serine 194 and association with a $70-\mathrm{kDa}$ cell cycle-regulated protein kinase. J Immunol 2000;164: $1236-1242$. $\checkmark 7$ Zhang J, Cado D, Chen A, Kabra NH, Winoto A: Fas-mediated apoptosis and activationinduced T-cell proliferation are defective in mice lacking FADD/MORT1. Nature 1998; 392:296-300.

$\checkmark 8$ Zhang J, Kabra NH, Cado D, Kang C, Winoto A: FADD-deficient T cells exhibit a disaccord in regulation of the cell cycle machinery. J Biol Chem 2001;276:29815-29818.

$>9$ Shimada K, Matsuyoshi S, Nakamura M, Ishida E, Konishi N: Phosphorylation status of Fas-associated death domain-containing protein (FADD) is associated with prostate cancer progression. J Pathol 2005;206:423432.

10 Shay JW, Wright WE: Senescence and immortalization: role of telomeres and telomerase. Carcinogenesis 2005;26:867-874.

11 Shimada K, Matsuyoshi S, Nakamura M, Ishida E, Kishi M, Konishi N: Phosphorylation of FADD is critical for sensitivity to anticancer drug-induced apoptosis. Carcinogenesis 2004;25:1089-1097.

12 Sabeh F, Ota I, Holmbeck K, Birkedal-Hansen H, Soloway P, Balbin M, Lopez-Otin C, Shapiro S, Inada M, Krane S, Allen E, Chung D, Weiss SJ: Tumor cell traffic through the extracellular matrix is controlled by the membrane-anchored collagenase MT1MMP. J Cell Biol 2004;167:769-781.

13 Shimada K, Nakamura M, Ishida E, Higuchi T, Yamamoto H, Tsujikawa K, Konishi N: Prostate cancer antigen-1 contributes to cell survival and invasion though discoidin receptor 1 in human prostate cancer. Cancer Sci 2008;99:39-45.
14 Greider CW, Blackburn EH: Identification of a specific telomere terminal transferase activity in Tetrahymena extracts. Cell 1985;43: 405-413.

15 Greider CW, Blackburn EH: A telomeric sequence in the RNA of Tetrahymena telomerase required for telomere repeat synthesis. Nature 1989;337:331-337.

$>16$ Kilian A, Bowtell DD, Abud HE, Hime GR, Venter DJ, Keese PK, Duncan EL, Reddel RR, Jefferson RA: Isolation of a candidate human telomerase catalytic subunit gene, which reveals complex splicing patterns in different cell types. Hum Mol Genet 1997;6:20112019.

17 Feng J, Funk WD, Wang SS, Weinrich SL, Avilion AA, Chiu CP, Adams RR, Chang E, Allsopp RC, Yu J, et al: The RNA component of human telomerase. Science 1995;269: 1236-1241.

18 Harrington L, McPhail T, Mar V, Zhou W, Oulton R, Bass MB, Arruda I, Robinson MO: A mammalian telomerase-associated protein. Science 1997;275:973-977.

19 Ducrest AL, Szutorisz H, Lingner J, Nabholz M: Regulation of the human telomerase reverse transcriptase gene. Oncogene 2002;21: 541-552.

20 Juo P, Woo MS, Kuo CJ, Signorelli P, Biemann HP, Hannun YA, Blenis J: FADD is required for multiple signaling events downstream of the receptor Fas. Cell Growth Differ 1999;10:797-804. 
21 Chen G, Bhojani MS, Heaford AC, Chang DC, Laxman B, Thomas DG, Griffin LB, Yu J, Coppola JM, Giordano TJ, Lin L, Adams D, Orringer MB, Ross BD, Beer DG, Rehemtulla A: Phosphorylated FADD induces NF- $\mathrm{B}$, perturbs cell cycle, and is associated with poor outcome in lung adenocarcinomas. Proc Natl Acad Sci USA 2005;102:1250712512.

22 Amit S, Ben-Neriah Y: NF-кB activation in cancer: a challenge for ubiquitination- and proteasome-based therapeutic approach. Semin Cancer Biol 2003;13:15-28.

23 Sheikh MS, Huang Y: The FADD is going nuclear. Cell Cycle 2003;2:346-347.
24 Kabra NH, Kang C, Hsing LC, Zhang J, Winoto A: T cell-specific FADD-deficient mice: FADD is required for early $\mathrm{T}$ cell development. Proc Natl Acad Sci USA 2001;98:63076312.

25 Gomez-Angelats M, Cidlowski JA: Molecular evidence for the nuclear localization of FADD. Cell Death Differ 2003;10:791-797.

-26 Screaton RA, Kiessling S, Sansom OJ, Millar CB, Maddison K, Bird A, Clarke AR, Frisch SM: Fas-associated death domain protein interacts with methyl-CpG binding domain protein 4: a potential link between genome surveillance and apoptosis. Proc Natl Acad Sci USA 2003;100:5211-5216.

-27 Shimada K, Nakamura M, Ishida E, Kishi M, Matsuyoshi S, Konishi N: The molecular mechanism of sensitization to Fas-mediated apoptosis by 2-methoxyestradiol in PC3 prostate cancer cells. Mol Carcinog 2004;39: $1-9$.
28 Petrylak DP, Tangen CM, Hussain MH, Lara PN Jr, Jones JA, Taplin ME, Burch PA, Berry D, Moinpour C, Kohli M, Benson MC, Small EJ, Raghavan D, Crawford ED: Docetaxel and estramustine compared with mitoxantrone and prednisone for advanced refractory prostate cancer. N Engl J Med 2004;351: 1513-1520.

29 Tannock IF, de Wit R, Berry WR, Horti J, Pluzanska A, Chi KN, Oudard S, Theodore C, James ND, Turesson I, Rosenthal MA, Eisenberger MA: Docetaxel plus prednisone or mitoxantrone plus prednisone for advanced prostate cancer. N Engl J Med 2004; 351:1502-1512. 